\title{
Partial Splenic Artery Embolization in Cirrhosis Is a Safe and Useful Procedure
}

\author{
Fakhar Ali Qazi Arisar1*, Syed Hasnain Ali Shah1, Tanveer Ul Haq² \\ ${ }^{1}$ Section of Gastroenterology, Department of Medicine, The Aga Khan University Hospital, Karachi, Pakistan \\ ${ }^{2}$ Section of Interventional Radiology, Department of Radiology, The Aga Khan University Hospital, Karachi, Pakistan \\ Email: ^fakhar.qazi@aku.edu, hasnain.alishah@aku.edu, tanveer.haq@aku.edu
}

How to cite this paper: Arisar, F.A.Q., Shah, S.H.A. and Haq, T.U. (2018) Partial Splenic Artery Embolization in Cirrhosis Is a Safe and Useful Procedure. Open Journal of Gastroenterology, 8, 327-336. https://doi.org/10.4236/ojgas.2018.89035

Received: August 23, 2018

Accepted: September 23, 2018

Published: September 26, 2018

Copyright ( 92018 by authors and Scientific Research Publishing Inc. This work is licensed under the Creative Commons Attribution International License (CC BY 4.0).

http://creativecommons.org/licenses/by/4.0/

(c) (i) Open Access

\begin{abstract}
Background: Portal Hypertension is a common complication of cirrhosis. It leads to splenomegaly which manifests with features of hypersplenism. This results in leucopenia which increases the likelihood of sepsis and prevents treatment with interferon. Thrombocytopenia increases the risk of bleeding including variceal bleeds which make the anemia worse. This study was done to determine the usefulness and safety of partial splenic artery embolization (PSAE) in portal hypertension due to cirrhosis. Methods: Patients with PSAE were identified by using International Classification of Diseases (ICD)-10 coding from medical records and their charts were reviewed retrospectively. 25 patients underwent splenic artery embolization at The Aga Khan University Hospital Karachi from November 2000 to December 2016. 18 patients who underwent PSAE for disabling hypersplenism caused by cirrhosis were included. Patients who were under 18 year of age, or in whom PSAE were performed for reasons other than cirrhosis and those with missing records/incomplete data were excluded $(n=7)$. Information was collected regarding demographic details, procedure indications, nature, technique, clinical efficacy, repeat embolization and complications along with laboratory and radiological investigations. Results: Eighteen patients of cirrhosis with a mean age of $43.47 \pm 10.926$ years, of which 14 were males, underwent PSAE (19 procedures). Indications were severe hypersplenism which precluded treatment with interferon and ribavirin $(\mathrm{n}=8)$ and recurrent Gastro-oesophageal variceal (GOV) bleeds due to advanced Child-Pugh grade and thrombocytopenia $(\mathrm{n}=10)$. Hematological parameters improved significantly following PSAE. Three out of eight patients successfully completed interferon + ribavirin treatment for hepatitis C $(\mathrm{HCV})$ infection post PSAE, and GOV bleeds stopped in eight out of 10 patients. Complications included mild Left upper quadrant (LUQ) abdominal pain $\mathrm{n}=9$ (47.3\%), post-embolization syndrome $n=4(21 \%)$, and clinically insignificant pleural
\end{abstract}


effusion $n=4(21 \%)$. One patient developed spontaneous bacterial peritonitis (SBP) which was appropriately managed. One patient needed re-emobilization after 6 months. Conclusion: PSAE is a safe and effective procedure in the treatment of hypersplenism due to cirrhosis.

\section{Keywords}

Partial Splenic Artery Embolization, Chronic Liver Disease, Cirrhosis, Hypersplenism, Safety, Outcome

\section{Introduction}

Hypersplenism occurs in the majority of patients suffering from cirrhosis and portal hypertension [1]. Splenic pooling and sequestration of blood cells lead to cytopenias, which precludes them from treatment options for chronic viral hepatitis or any invasive procedure/surgeries and also makes them prone to recurrent GI bleed.

Currently partial splenic artery embolization (PSAE) is an approved minimally invasive intervention for management of portal hypertension, gastric variceal hemorrhage, hypersplenism, control of splenic hemorrhage from trauma or prior to surgical resection, idiopathic thrombocytopenic purpura, splenic artery aneurysms or pseudoaneurysms, and splenic steal syndrome (nonocclusive hepatic artery hypoperfusion syndrome [NOHAH]) in liver transplant recipients [2] [3] [4].

Splenic artery embolization interrupts arterial flow to the splenic artery or to one of its branches; it may be considered as an alternative, either to splenectomy or to ligation of the splenic artery. Total splenectomy may be a useful cure for hypersplenism, but it is associated with perioperative complications and also impairs the capability of the body to create antibodies against encapsulated microorganisms, thus making the individual prone to sepsis. Many authors have advocated incomplete or partial embolization (PSAE), in which a segment of the splenic parenchyma is left viable to maintain the immunologic function [3] [5].

Splenic artery embolization was introduced in 1973 as a nonsurgical treatment for variceal hemorrhage and hypersplenism [6]. Six years after this initial report, Spigos et al. treated patients with partial splenic artery embolization using antibiotic coverage and post-embolization pain control [7]. The process helps occlude the arterial supply of the spleen more peripherally, which results in ischemic necrosis of much of the functional spleen leading to a reduction in splenic size and consequently counters hypersplenism. Initially the application of procedure remained limited because of the high rate of morbidity and mortality, but later on, the outcomes improved once partial embolization and antibiotic coverage were adopted [2] [3]. This technique can be used safely when total embolization volume is $\sim 50 \%$ and the procedural and peri-procedural time periods are covered with antibiotics [2]. Also, it is a simple, and rapid procedure 
that can be performed easily under local anesthesia and incurs less morbidity, and there is no need for blood transfusion [5].

The current study is planned with the purpose of providing a detailed assessment of the safety, effectiveness, and clinical outcome in cirrhotic patients who underwent PSAE. To the best of our knowledge, no such study has yet been carried out in Pakistan and it will definitely be a good addition in the upcoming literature from our country.

\section{Material and Methods}

\subsection{Patients}

Patients with PSAE were identified by using International Classification of Diseases (ICD)-10 coding from medical records and their charts were reviewed retrospectively. 25 patients underwent splenic artery embolization at The Aga Khan University Hospital Karachi from November 2000 to December 2016. 18 patients who underwent PSAE for disabling hypersplenism caused by cirrhosis were included. Patients who were under 18 year of age, or in whom PSAE was performed for reasons other than cirrhosis, and those with missing records/incomplete data were excluded $(n=7)$.

Information was collected regarding age, gender, primary and secondary outcomes, length of hospital stay, comorbid conditions, procedure indications, nature, technique, clinical efficacy, repeat embolization and complications along with laboratory and radiological investigations. This study was granted exemption from ethical approval by the institutional ethical review committee of The Aga Khan University Hospital, Pakistan.

\subsection{Pre-Procedure Preparation}

The day before examination the patients were admitted to the hospital. Their laboratory data were revised and they were started on antibiotics (ceftriaxone $2 \mathrm{~g}$ IV OD). Six units of platelets were given the night before the examination. Prophylactic vaccination was not given to any patient.

\subsection{Embolization Protocol}

The PSAE procedures were performed in the interventional radiology suite. After standard preparation, under local anesthesia, the percutaneous arterial access was obtained with Seldinger's technique (4F introducer). The celiac trunk and the splenic artery were selectively catheterized with a 4F C1 catheter. Embolization was then done by administration of polyvinyl alcohol (PVA) particles. The size of the particles of embolization ranged from 255 to 710 micron. The infarction volume was estimated by a selective angiogram showing the reduction in the splenic vascularization and the residual spleen parenchyma.

\subsection{Follow-Up}

The post-procedure follow-up was analyzed retrospectively from the medical 
case notes. Post-PSAE supportive care included appropriate hydro-electrolytic infusion, systemic prophylaxis with antibiotics, using ceftriaxone within hospital and cefixime (400 mg/day) on discharge for at least 5 days, and analgesic treatment using paracetamol or tramadol. All patients stayed in hospital after PSAE until they became clinically stable, and were then followed up at the outpatient clinic. Peripheral blood cell parameters including hemoglobin ( $\mathrm{Hb})$, white blood cell count (WBC), and platelet count were monitored on the 3rd, 14th, 30th day after PSAE, and subsequently at 3-month intervals during the 1-year follow-up period.

\subsection{Outcome}

- Primary outcome: technically and clinically successful embolization, defined by the ability to resume or begin treatment that induces pancytopenia (such as interferon), and the prevention or reduction of recurrent bleeding.

- Secondary outcome: morbidity and mortality related to PSAE.

\subsection{Statistical Analysis}

Data were entered in a commercial statistical software package (IBM SPSS Statistics for Windows, version 19.0). The results were expressed as means \pm standard deviations or median \pm range for quantitative variables, and compared according to the volume of embolized parenchyma. Proportions were calculated for qualitative variables. $\mathrm{Hb}$, platelet count and WBC count pre and post-PSAE were compared using a pairedt-test. The association between the splenic infarction rate and the rate of increase in blood cell counts was analyzed by the Spearman rank correlation coefficient (rsp). Significance was established at $\mathrm{P}<$ 0.05 .

\section{Results}

A total of 19 procedures were performed on 18 cirrhotic patients. $14(77.7 \%)$ were male, age between 15 to 64 years (mean age: $43.47 \pm 10.926$ years). The indication of parenchymal reduction for eight patients was cytopenias too severe to initiate or continue treatment with interferon and ribavirin $(\mathrm{Hb}<10 \mathrm{~g} / \mathrm{dl}$ or platelets $<90 \times 10^{9} / \mathrm{L}$ ) [8] [9]; 10 cases presented with recurrent gastrointestinal bleeding with severe thrombocytopenia.

The baseline characteristics of the total cohort of PSAE-treated patients are shown in Table 1. Nine patients each were classified as Child-Pugh Class A and $B$ [10] [11]. The etiologic factors of cirrhosis were hepatitis $C$ in 15 patients and hepatitis B in 2 patients, while one patient had Non-B, Non-C related cirrhosis. 13 patients had esophageal varices. No HCC was detected in the study subjects before PSAE.

All procedures were done electively except for one who underwent emergency embolization due to failure to control upper GI bleed by endoscopic variceal band ligation (EVBL). PSAE was effectively performed in all patients with 
Table 1. Baseline characteristics of the total cohort of psae-treated patients.

\begin{tabular}{|c|c|c|}
\hline \multicolumn{2}{|c|}{ Variables } & \multirow{2}{*}{$\begin{array}{l}\mathrm{n}=18(\%) \\
14(77.7 \%)\end{array}$} \\
\hline & Male & \\
\hline Gender & Female & $4(22.3 \%)$ \\
\hline \multirow{4}{*}{ Etiology } & $\mathrm{HCV}$ & $15(83.3 \%)$ \\
\hline & HBV & $1(5.5 \%)$ \\
\hline & $\mathrm{HBV}+\mathrm{HDV}$ & $1(5.5 \%)$ \\
\hline & NBNC & $1(5.5 \%)$ \\
\hline \multirow{4}{*}{ Co-morbid } & DM & $4(22.3 \%)$ \\
\hline & HTN & $5(27.7 \%)$ \\
\hline & IHD & $1(5.5 \%)$ \\
\hline & Hereditary spherocytosis & $1(5.5 \%)$ \\
\hline \multirow{2}{*}{ Child Class } & A & $9(50 \%)$ \\
\hline & B & $9(50 \%)$ \\
\hline \multirow{3}{*}{ Esophageal varices } & Absent & $5(27.7 \%)$ \\
\hline & Small & $3(16.6 \%)$ \\
\hline & Large & $10(55.5 \%)$ \\
\hline \multirow{2}{*}{ Indication } & Upper GI Bleed & $10(55.5 \%)$ \\
\hline & $\mathrm{HCV}$ treatment & $8(44.5 \%)$ \\
\hline \multirow{2}{*}{ Nature of procedure } & Urgent & $1(5.5 \%)$ \\
\hline & Elective & $17(94.5 \%)$ \\
\hline \multirow{4}{*}{ PVA particles (micron) } & $255-300$ & $1(5.5 \%)$ \\
\hline & $355-500$ & $6(33.3 \%)$ \\
\hline & $500-710$ & $11(61.1 \%)$ \\
\hline & Both $355-500 \& 500-710$ & $1(5.5 \%)$ \\
\hline Percentage embolization volume & $($ mean $\pm S D)$ & $37.22 \pm 7.321$ \\
\hline Length of stay in days & (Median + Range) & $02(01-25)$ \\
\hline Follow up in days & (Median + Range) & $304(07-1126)$ \\
\hline
\end{tabular}

HBV: Hepatitis B virus; HCV: Hepatitis C virus; HDV: Hepatitis D virus; NBNC: Non-Hepatitis B, Non-HepatitisC; DM: Diabetes mellitus; HTN: Hypertension; IHD: Ischemic heart disease; PVA: Polyvinyl alcohol.

percentage embolization volume ranging from $30 \%$ to $50 \%$. Patients were followed up for a median period of 304 (Range: 07 - 1126) days after the procedure. Repeat procedure was only necessary for one patient due to persistent thrombocytopenia.

Irrespective of the percentage embolization volume, all cell lineages improved significantly immediately after PSAE until 1 week. After which a progressive decline was noted in all cell counts as shown in Table 2. However, despite a decrease in counts, leukocytes and platelets remained persistently improved at 1 month, 6 months and until 1 year of follow up with a significant difference from baseline (P-value of 0.003 and 0.003 at 1 month, 0.017 and $<0.001$ at 6 months and 0.006 and 0.03 at 1 year respectively). The average maximum spleen length before PSAE was $150.34 \pm 67.36 \mathrm{~cm}$, while after 4 weeks of PSAE, it was $136.0 \pm$ $65.18 \mathrm{~cm}$.

Antiviral treatment with interferon was started after an adequate rise in cell counts in five patients, of which 3 were successfully able to complete the full 
Table 2. Comparison of pre- and post-procedure spleen size and hematologic parameters.

\begin{tabular}{|c|c|c|c|c|c|c|}
\hline & \multirow{2}{*}{$\begin{array}{c}\text { Pre PSAE } \\
(\text { Mean } \pm \mathrm{SD})\end{array}$} & \multicolumn{5}{|c|}{ Post PSAE (Mean \pm SD) } \\
\hline & & 1 Day & 1 Week & 4 Weeks & 26 Weeks & 52 Weeks \\
\hline $\mathrm{n}$ & 18 & 17 & 17 & 17 & 15 & 10 \\
\hline $\begin{array}{l}\text { Spleen size } \\
\quad(\mathrm{mm})\end{array}$ & $150.34 \pm 67.37$ & & & $\begin{array}{c}136.00 \pm 65.18 \\
P=0.079\end{array}$ & & \\
\hline $\begin{array}{l}\text { Hemoglobin } \\
\quad(\mathrm{g} / \mathrm{dl})\end{array}$ & $10.47 \pm 2.13$ & $11.33 \pm 2.06$ & $11.62 \pm 1.49$ & $\begin{array}{c}11.18 \pm 1.75 \\
P=0.113\end{array}$ & $\begin{array}{c}10.68 \pm 1.73 \\
P=0.311\end{array}$ & $\begin{array}{c}12.4 \pm 1.74 \\
\mathrm{P}=0.08\end{array}$ \\
\hline $\begin{array}{c}\text { White blood } \\
\text { cells } \\
\left(\times 10^{9} / \mathrm{L}\right)\end{array}$ & $3.29 \pm 0.93$ & $8.02 \pm 5.57$ & $9.12 \pm 6.99$ & $\begin{array}{c}5.46 \pm 2.39 \\
P=0.003\end{array}$ & $\begin{array}{l}4.8 \pm 2.23 \\
P=0.017\end{array}$ & $\begin{array}{l}5.2 \pm 1.42 \\
P=0.006\end{array}$ \\
\hline $\begin{array}{l}\text { Platelets } \\
\left(\times 10^{9} / \mathrm{L}\right)\end{array}$ & $38.11 \pm 15.41$ & $54 \pm 23.39$ & $116 \pm 79.87$ & $\begin{array}{c}107.93 \pm 74.71 \\
P=0.003\end{array}$ & $\begin{array}{c}63.92 \pm 14.94 \\
P \leq 0.001\end{array}$ & $\begin{array}{c}91.33 \pm 61.21 \\
P=0.03\end{array}$ \\
\hline
\end{tabular}

PSAE: Partial splenic artery embolization.

duration of treatment as described in Table 3. Of the other 2 patients, 1 got decompensated with ascites while other was lost to follow-up. In three patients, planned antiviral treatment was not started due to persistent thrombocytopenia $(\mathrm{n}=2)$ and anemia $(\mathrm{n}=1)$. The overallprimary outcome of PSAE was achieved in 13 (72\%) patients (upper GI bleed control: $\mathrm{n}=8$, resume/begin interferon therapy: $\mathrm{n}=5)$.

The median hospital stay after PSAE was 2 days (range from 1 to 25 days). The pain was the most common complication occurring in $9(47.3 \%)$ patients followed by post-embolization syndrome [12] characterized by fever and abdominal pain in 4 (21\%) patients (Table 4). Mild pleural effusion was noticed in 4 (21\%) patients, which was picked up on follow-up images without any clinical symptom and sign. One patient had spontaneous bacterial peritonitis (SBP) and sepsis post procedure leading to prolong hospital stay. None of the patients developed splenic abscess. No immediate or late procedure-related mortality occurred in our patients on follow-up. No relation of percentage volume embolization with the development of complications was found.

\section{Discussion}

Pakistan has been labeled as a cirrhotic state long ago [13], with hepatitis $C$ being the commonest cause $(60 \%-90 \%)$ according to recent data [14] [15] [16]. According to a study, $68 \%$ of the cirrhotic patients in Pakistan were found to have hypersplenism [1].

The published efficacy rates for splenic artery embolization are fairly high; a recent meta-analysis of splenic artery embolization in the non-operative management of blunt splenic trauma found an overall failure rate of $15.7 \%$ [17], while success in the treatment of splenic arterial aneurysms and pseudoaneurysms is approximately 90\% [18] [19] [20]. In patients with portal hypertension and hypersplenism, splenic artery embolization has been shown to produce 
Table 3. Primary outcomes achieved after PSAE.

\begin{tabular}{ccc}
\hline Outcomes & $\mathbf{n}$ & $\%$ \\
\hline Upper GI Bleed control & $7 / 9$ & $77.7 \%$ \\
For recurrent bleed & $1 / 1$ & $100 \%$ \\
For acute bleed & $5 / 8$ & $62.5 \%$ \\
Interferon started & $3 / 5$ & $60 \%$ \\
Interferon completed & $1 / 17$ & $5.8 \%$ \\
Re-embolization (After 6 months) & & \\
\hline
\end{tabular}

Table 4. Morbidity after PSAE.

\begin{tabular}{ccc}
\hline Complications & $\mathrm{n}$ & $\begin{array}{c}\text { Percentage of total procedures } \\
\text { (out of 19) }\end{array}$ \\
\hline Pain & 09 & $47.4 \%$ \\
Post-embolization syndrome & 04 & $21.1 \%$ \\
Clinically insignificant pleural effusion & 04 & $21.1 \%$ \\
Initial thrombocytopenia & 02 & $21.1 \%$ \\
SBP, sepsis and prolong hospital stay & 01 & $11.1 \%$ \\
\hline
\end{tabular}

significant and sustained improvements in both liver function and hematologic indices, as well as an $80 \%$ reduction in annual bleeding episodes in patients with recurrent variceal hemorrhage [21] [22].

PVA particles were used for embolization in our patients, ranging from 250 to 710 micron in size. Although gel-foam particles are also reported to be used by other researchers and found equivalent to PVA in terms of outcomes [23], the embolization volume was determined by confirming a reduction in the splenic vascularization using selective angiogram. The extent of embolization varied between $30 \%-50 \%$ (mean $37.22 \pm 7.321$ ) which according to the literature is sufficient to cause infarction of around $70 \%-80 \%$ of splenic parenchyma [24].

The highest mean values of $\mathrm{WBC}$ and platelets were recorded at 1-week post-PSAE, after which a gradual decline was noted for next 6 month followed by steady levels. The initial rapid rise could be either due to the release of platelets sequestered by spleen and splenic regeneration could have explained the gradual decline in platelets [24]. Initial leukocytosis could be due to an inflammatory process against infarcted spleen [25] [26]. Neither the percent embolized volume nor any other factor was found to be related with an increase in platelet count or WBC. Hayashi et al. also did not find any factor related to increase cell counts except infarcted splenic volume [27].

Our study supports the utilization of PSAE in controlling GI bleed. We demonstrated control of recurrent GI bleed in 7 out of 9 patients (77\%) which is consistent with previous reports [4] [22].

Although serum albumin concentration was reported to rise after PSAE by some authors, no major change in liver enzymes is described [28]. We also did not find any significant impact on liver functions in patients undergoing PSAE consistent with the previous reports [24] [29] [30]. 
Post-embolization syndrome occurred in only four patients $(22 \%)$ which is much lower than what was noted in previous studies (95\% - 100\%) [5] [23] [29] [31]. The reported mortality rate of PSAE is around 4\% [32], while major complications are reported up to $17 \%$ [33]. In our cohort, no mortality was reported; however, one patient had sepsis and SBP requiring to prolong hospital stay.

Child C disease has been associated with complications after PSAE [31] [33]. However, none of the patients in our cohort belonged to child class C. Advanced age and post-procedure hydrothorax are the other factors related to mortality [4]. However, we were unable to identify any significant relationship between mortality and these factors.

Retrospective nature is the major weaknesses of this study. Other limitations include a small sample size, single center data collection, and non-randomized design. The long duration of enrollment and prolonged follow-up of patients are the major strengths of our study.

\section{Conclusion}

PSAE is a safe and effective procedure in the treatment of hypersplenism of cirrhosis.

\section{Conflicts of Interest}

No conflict of interest to disclose from all authors.

\section{Supported Foundation}

Not applicable.

\section{Author's Contributions}

Qazi Arisar FA designed and performed the research and wrote the manuscript. Shah SHA designed the research and supervised the manuscript. All authors agreed with the content of the manuscript. Haq TU designed the research, performed PSAE procedures and supervised the manuscript.

\section{References}

[1] Ashraf, S. and Naeem, S. (2010) Frequency of Hypersplenism in Chronic Liver Disease Patients Presenting with Pancytopenia. Annals of King Edward Medical University, 16, 108-110.

[2] Smith, M. and Ray, C.E. (2012) Splenic Artery Embolization as an Adjunctive Procedure for Portal Hypertension. Seminars in Interventional Radiology, 29, 135-139. https://doi.org/10.1055/s-0032-1312575

[3] Madoff, D.C., Denys, A., Wallace, M.J., Murthy, R., Gupta, S., Pillsbury, E.P., et al. (2005) Splenic Arterial Interventions: Anatomy, Indications, Technical Considerations, and Potential Complications. RadioGraphics, 25, S191-S211. https://doi.org/10.1148/rg.25si055504

[4] Gaba, R.C., Katz, J.R., Parvinian, A., Reich, S., Omene, B.O., Yap, F.Y., et al. (2013) Splenic Artery Embolization: A Single Center Experience on the Safety, Efficacy, 
and Clinical Outcomes. Diagnostic and Interventional Radiology, 19, 49-55.

[5] Amin, M.A., El Gendy, M.M., Dawoud, I.E., Shoma, A., Negm, A.M. and Amer, T.A. (2009) Partial Splenic Embolization versus Splenectomy for the Management of Hypersplenism in Cirrhotic Patients. World Journal of Surgery, 33, 1702-1710. https://doi.org/10.1007/s00268-009-0095-2

[6] Maddison, F.E. (1973) Embolic Therapy of Hypersplenism. Investigative Radiology, 8, 280-281. https://doi.org/10.1097/00004424-197307000-00054

[7] Spigos, D., Jonasson, O., Mozes, M. and Capek, V. (1979) Partial Splenic Embolization in the Treatment of Hypersplenism. American Journal of Roentgenology, 132, 777-782. https://doi.org/10.2214/ajr.132.5.777

[8] (2011) EASL Clinical Practice Guidelines: Management of hepatitis C Virus Infection. Journal of Hepatology, 55, 245-264.

https://doi.org/10.1016/j.jhep.2011.02.023

[9] AASLD-IDSA Recommendations for Testing, Managing, and Treating Hepatitis C. http://www.hcvguidelines.org

[10] Child, C.G. and Turcotte, J.G. (1964) Surgery and Portal Hypertension. Major Problems in Clinical Surgery, 1, 1-85.

[11] Pugh, R.N., Murray-Lyon, I.M., Dawson, J.L., Pietroni, M.C. and Williams, R. (1973) Transection of the Oesophagus for Bleeding Oesophageal Varices. British Journal of Surgery, 60, 646-649.

[12] Sakai, T., Shiraki, K., Inoue, H., Sugimoto, K., Ohmori, S., Murata, K., et al. (2002) Complications of Partial Splenic Embolization in Cirrhotic Patients. Digestive Diseases and Sciences, 47, 388-391. https://doi.org/10.1023/A:1013786509418

[13] Ahmad, K. (2004) Pakistan: A Cirrhotic State? The Lancet, 364, 1843-1844. https://doi.org/10.1016/S0140-6736(04)17458-8

[14] Fahim, U., Khan, S., Afridi, A.K. and ur Rahman, S. (2012) Frequency of Different Causes of Cirrhosis of Liver in Local Population. Gomal Journal of Medical Sciences, 10, 178-181.

[15] Arisar, F.A.Q., Khan, S.B. and Umar, A. (2014) Hepatic Encephalopathy in Chronic Liver Disease: Predisposing Factors in a Developing Country. Asian Journal of Medical Sciences, 6, 35-42.

[16] Umar, A., Arisar, F.A.Q., Sattar, R.A. and Umar, B. (2014) Non-Invasive Parameters for the Detection of Variceal Bleed in Patients of Liver Cirrhosis, an Experience of a Tertiary Care Hospital in Pakistan. Asian Journal of Medical Sciences, 6, 61-66. https://doi.org/10.3126/ajms.v6i1.9624

[17] Requarth, J.A., D’Agostino Jr., R.B. and Miller, P.R. (2011) Nonoperative Management of Adult Blunt Splenic Injury with and without Splenic Artery Embolotherapy: A Meta-Analysis. Journal of Trauma and Acute Care Surgery, 71, 898-903. https://doi.org/10.1097/TA.0b013e318227ea50

[18] Loffroy, R., Guiu, B., Cercueil, J.-P., Lepage, C., Cheynel, N., Steinmetz, E., et al. (2008) Transcatheter Arterial Embolization of Splenic Artery Aneurysms and Pseudoaneurysms: Short- and Long-Term Results. Annals of Vascular Surgery, 22, 618-626. https://doi.org/10.1016/j.avsg.2008.02.018

[19] Belli, A.-M., Markose, G. and Morgan, R. (2012) The Role of Interventional Radiology in the Management of Abdominal Visceral Artery Aneurysms. CardioVascular and Interventional Radiology, 35, 234-243. https://doi.org/10.1007/s00270-011-0201-3

[20] McDermott, V.G., Shlansky-Goldberg, R. and Cope, C. (1994) Endovascular Man- 
agement of Splenic Artery Aneurysms and Pseudoaneurysms. CardioVascular and Interventional Radiology, 17, 179-184. https://doi.org/10.1007/BF00571531

[21] Hirai, K., Kawazoe, Y., Yamashita, K., Kumagai, M., Tanaka, M., Sakai, T., et al. (1986) Transcatheter Partial Splenic Arterial Embolization in Patients with Hypersplenism: A Clinical Evaluation as Supporting Therapy for Hepatocellular Carcinoma and Liver Cirrhosis. Hepatogastroenterology, 33, 105-108.

[22] Koconis, K.G., Singh, H. and Soares, G. (2007) Partial Splenic Embolization in the Treatment of Patients with Portal Hypertension: A Review of the English Language Literature. Journal of Vascular and Interventional Radiology, 18, 463-481. https://doi.org/10.1016/j.jvir.2006.12.734

[23] Albadry, A., Elbatea, H.E. and Elfert, A.A. (2010) Long-Term Outcome of Angiographic Partial Splenectomy in Patients with Decompensated Liver Cirrhosis and Hypersplenism. Arab Journal of Gastroenterology, 11, 202-205.

https://doi.org/10.1016/j.ajg.2010.09.004

[24] Nassef, A.A., Zakaria, A.A. and ElBary, M.S.A. (2013) Partial Splenic Artery Embolization in Portal Hypertension Patients with Hypersplenism: Two Interval-Spaced Sessions' Technique. The Egyptian Journal of Radiology and Nuclear Medicine, 44, 531-537. https://doi.org/10.1016/j.ejrnm.2013.04.004

[25] Sundaresan, J.B., Dutta, T., Badrinath, S., Jagdish, S. and Basu, D. (2005) Study of Hypersplenism and Effect of Splenectomy on Patients with Hypersplenism. Journal of Indian Academy of Clinical Medicine, 6, 291-296.

[26] McCormick, P.A. (2007) Hypersplenism. Textbook of Hepatology: From Basic Science to Clinical Practice, 3rd Edition, 771-778.

[27] Hayashi, H., Beppu, T., Masuda, T., Mizumoto, T., Takahashi, M., Ishiko, T., et al. (2007) Predictive Factors for Platelet Increase after Partial Splenic Embolization in Liver Cirrhosis Patients. Journal of Gastroenterology and Hepatology, 22, 1638-1642. https://doi.org/10.1111/j.1440-1746.2007.05090.x

[28] Tajiri, T., Onda, M., Yoshida, H., Mamada, Y., Taniai, N. and Kumazaki, T. (2002) Long-Term Hematological and Biochemical Effects of Partial Splenic Embolization in Hepatic Cirrhosis. Hepatogastroenterology, 49, 1445-1448.

[29] Zhu, K., Meng, X., Qian, J., Huang, M., Li, Z., Guan, S., et al. (2009) Partial Splenic Embolization for Hypersplenism in Cirrhosis: A Long-Term Outcome in $62 \mathrm{~Pa}$ tients. Digestive and Liver Disease, 41, 411-416. https://doi.org/10.1016/j.dld.2008.10.005

[30] Pålsson, B., Hallén, M., Forsberg, A.M. and Alwmark, A. (2003) Partial Splenic Embolization: Long-Term Outcome. Langenbeck's Archives of Surgery, 387, 421-426.

[31] Hussein, W.M., Ahmed, A.T., Magdy, M., Amer, T.A. and Habba, M.R. (2017) Predictive Factors of Platelet Increase and Complications after Percutaneous Trans-Arterial Partial Splenic Embolization for Hypersplenism in Chronic Liver Disease Patients. The Egyptian Journal of Radiology and Nuclear Medicine, 48, 393-401. https://doi.org/10.1016/j.ejrnm.2017.01.010

[32] Kumar, A., Yoon, J., Thakur, V. and Contractor, S. (2013) Abstract No. 317 Safety and Efficacy of Partial Splenic Embolization for Hypersplenism: A Meta-Analysis. Journal of Vascular and Interventional Radiology, 24, S138. https://doi.org/10.1016/j.jvir.2013.01.342

[33] Hayashi, H., Beppu, T., Okabe, K., Masuda, T., Okabe, H. and Baba, H. (2008) Risk Factors for Complications after Partial Splenic Embolization for Liver Cirrhosis. British Journal of Surgery, 95, 744-750. https://doi.org/10.1002/bjs.6081 